\title{
Traumatic rupture of retrosternal goiter: A rare case of acute superior mediastinal syndrome
}

\author{
Daniel Pop, MD, ${ }^{a}$ Nicolas Venissac, MD, ${ }^{a}$ Francesco Leo, MD, ${ }^{a}$ Babou Soilihi Karimdjee, MD, ${ }^{\text {a }}$ Fabrice Tiger, MD, ${ }^{\mathrm{b}}$ and \\ Jérôme Mouroux, MD, ${ }^{a}$ Nice and Antibes, France
}

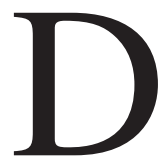

espite its benign nature, retrosternal goiter may compress the trachea and superior vena cava. ${ }^{1}$ The surgical indication becomes urgent after intracapsular hemorrhage. ${ }^{2,3} \mathrm{We}$ report the first case of traumatic extrathyroid bleeding causing a superior mediastinal syndrome.

\section{Clinical Summary}

A 76-year-old woman was admitted to the emergency department. While driving her car $(50 \mathrm{~km} / \mathrm{h})$, she had had a frontal collision with a stone wall. She was wearing a seat belt, but the airbag did not deploy. An eye witness saw her leaving the car with no difficulty, but 10 minutes later, the paramedics found her in respiratory and neurologic distress. Glasgow Coma Scale score was 3, and her vital signs were as follows: pulse 130 beats/min, systolic arterial pressure $70 \mathrm{~mm} \mathrm{Hg}$, arterial oxygen saturation $82 \%$, and pupils bilaterally reactive. An orotracheal intubation was done, and she was transported to the hospital.

Physical examination showed no external injury. After fluid resuscitation, her vital signs improved (Glasgow Coma Scale score 12), but facial and neck swelling were noted, with a turgescent external jugular veins. Hematologic analysis showed a hematocrit of $29 \%$ and a hemoglobin of $10 \mathrm{~g} / \mathrm{L}$, with no other significant anomalies.

The chest radiograph showed a mediastinal superior enlargement with tracheal deviation. The chest computed tomographic (CT) scan revealed a mediastinal left-sided mass developing from the inferior pole of the thyroid lobe to the left main bronchus, with well-defined borders. The heterogeneous lesion was $96 \mathrm{~mm}$ in the great longitudinal axis with no iodine enhancement. The trachea and esophagus were displaced rightward, and the great vessels were displaced forward (Figure 1). Magnetic resonance imaging confirmed the inhomogeneous lesion and excluded spinal cord injury. Additional CT and magnetic resonance imaging did not find any intracranial or spine anomalies.

From the Thoracic Surgery Department, Pasteur Hospital, Nice, France, and the Anesthesiology and Critical Care Department, Regional Hospital, Antibes, France. ${ }^{\mathrm{b}}$

Received for publication June 9, 2004; accepted for publication June 23, 2004.

Address for reprints: Daniel Pop, MD, Thoracic Surgery Department, Pasteur Hospital, Building H, 30 Avenue de la Voie Romaine, 06002 Nice, France (E-mail: danielpopch@yahoo.com).

J Thorac Cardiovasc Surg 2005;129:460-1

$0022-5223 / \$ 30.00$

Copyright $\odot 2005$ by The American Association for Thoracic Surgery

doi:10.1016/j.jtcvs.2004.06.032

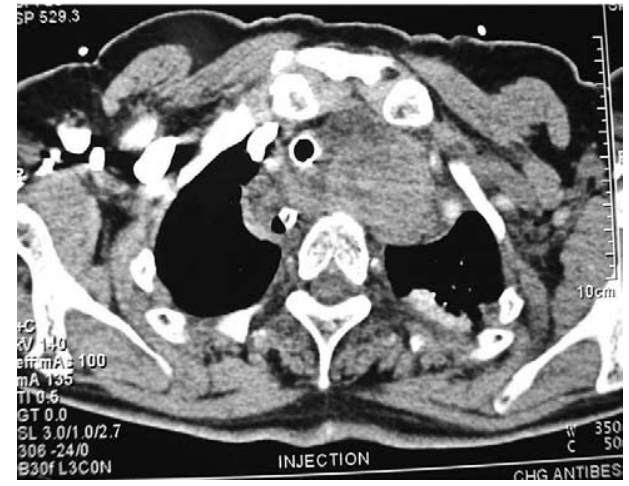

Figure 1. CT scan shows mediastinal compressive mass.

The woman was extubated 36 hours later, but a quick respiratory obstructive failure was evident. Examination with a flexible bronchoscope confirmed important compression of much of the length of the trachea (estimated at $60 \%$ ), necessitating reintubation. Of note, no abnormal blood levels of thyroid hormones were found. At that time our team was contacted, and the surgical indication was retained.

The patient was prepared for cervical and sternotomy approach. A collar neck incision revealed an endothoracic goiter attached to the inferior aspect of the left thyroid lobe, which had no evident abnormality. The goiter was digitally extracted with no difficulty. It had been torn in two pieces in the mediastinum, causing a compressive hematoma in the superior compartment (Figure 2). The histopathologic specimen measured $65 \times 40 \mathrm{~mm}$ and was determined to be an adenomatous heterovesicular goiter with areas of necrosis and hemorrhage. Further investigations showed elevated levels of antithyroglobulin (9201 UI/L, normally $<70 \mathrm{UI} / \mathrm{L})$ and antithyroperoxidase (1594 U/L, normally $<60 \mathrm{U} / \mathrm{L})$ antibodies, indicative of Hashimoto thyroiditis.

\section{Comment}

Substernal goiters grow slowly and cause few symptoms until they are quite large. A smaller group of patients have the acute onset of asphyxiation or superior vena caval syndrome as a result of the incarceration of mass in the thoracic inlet ${ }^{1,4}$ or the occurrence of intrathyroid spontaneous ${ }^{2}$ or traumatic ${ }^{3}$ hemorrhage.

Extracapsular bleeding can cause a rare extensive cervical hematoma. ${ }^{5}$ To the best of our knowledge, no case of mediastinal extracapsular hemorrhage from a substernal goiter has previously been described. Our case occurred in a traumatic instance. The seat belt was correctly worn but was directly responsible for the injury, because it concentrated the decelerating forces onto the trunk. The three possible mechanisms were as follows: the compression of the 


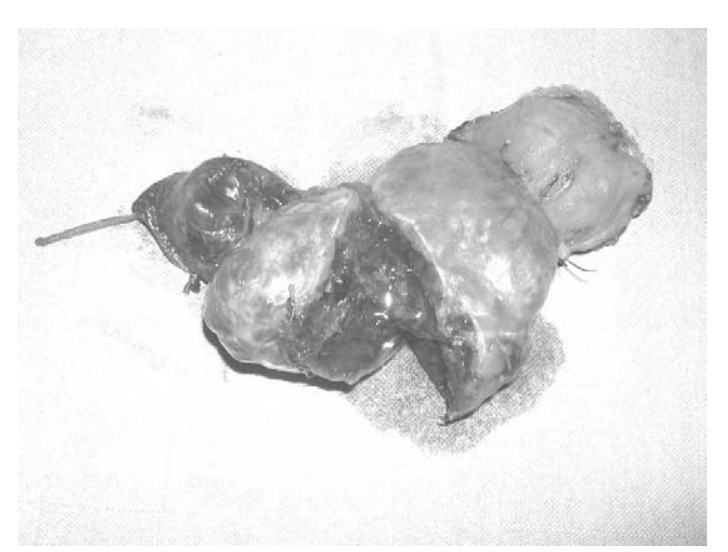

Figure 2. Operative goiter specimen, torn in two pieces.

unknown goiter in the thoracic inlet, the compression of goiter in the decreasing transversal diameter between the sternum and the dorsal spine from sudden flexion, or the mobility of the thyroid structure that crashed to the bony skeleton in the presence of a pathologic Hashimoto thyroid. The acute onset of an important mediastinal hematoma provoked the superior vena caval and tracheal compression responsible for the neurologic and respiratory distress.

Usually the CT pattern of intrathoracic goiter is sufficient for diagnosis. Eventually, magnetic resonance permits excellent delineation of the great vessels and their relationship with the goiter.
Unfortunately, neither could specify extrathyroid hemorrhage in our case. With no major source of mediastinal bleeding, a cervical approach was adopted.

The presence of a substernal goiter is an indication for surgery. In some instance of tracheal compression or superior vena caval syndrome, the surgery becomes an emergency. The most common operative approach is through the standard cervical collar incision, and the necessity of sternal approach is low, ranging from $2.5 \%$ to $9 \%$ of cases. ${ }^{1,4}$ Additional exposure is required for the following: mediastinal blood supply other than inferior cervical thyroid artery, uncontrolled hemorrhage, potential injury to the recurrent laryngeal nerves, large or posterior goiter, and low-lying carcinoma. According to Madjar and Weissberg, ${ }^{4}$ the acute state of symptoms is an indication for sternotomy. For us, the cervical incision has almost always been sufficient. However, the chest should be prepared for an eventually sternotomy if intraoperative findings lead to it.

\section{References}

1. Katlic MR, Wang CA, Grillo HC. Substernal goiter. Ann Thorac Surg. 1985;39:391-9.

2. Torres A, Arroyo J, Kastanos N, Estopa R, Rabaseda J, Agusti-Vidal A. Acute respiratory failure and tracheal obstruction in patients with intrathoracic goiter. Crit Care Med. 1983;11:265-6.

3. Georgiadis N, Katsas A, Leoutsakos KE. Substernal goiter. Int Surg. 1970;54:116-21.

4. Madjar S, Weissberg D. Retrosternal goiter. Chest. 1995;108:78-82.

5. Herman D, Piller P, Kennel P, Stierle JL, Conraux C. Extensive cervical hematoma complicating multinodular goiter. Apropos of a case [French]. Ann Otolaryngol Chir Cervicofac. 1992;109:105-7. 